\title{
The effect of prolonged darkness on the growth, recovery and survival of Antarctic sea ice diatoms
}

\author{
S. Reeves · A. McMinn • A. Martin
}

Received: 13 September 2010/Revised: 4 January 2011/Accepted: 5 January 2011/Published online: 25 January 2011

(c) Springer-Verlag 2011

\begin{abstract}
While global climate change in polar regions is expected to cause significant warming, the annual cycle of light and dark will remain unchanged. Cultures of three species of Antarctic sea ice diatoms, Fragilariopsis cylindrus (Grunow) Krieger, Thalassiosira antarctica Comber and Entomoneis kjellmanii (P.T. Cleve) Poulin and Cardinal, were incubated in the dark and exposed to differing temperatures. Maximum dark survival times varied between 30 and 60 days. Photosynthetic parameters, photosynthetic efficiency $(\alpha)$, maximum quantum yield (Fv/ Fm), maximum relative electron transport rate (rETRmax) and non-photochemical quenching (NPQ), showed that dark exposure had a significant impact on photoacclimation. In contrast, elevated temperatures had a relatively minor impact on photosynthetic functioning during the dark exposure period but had a considerable impact on dark survival with minimal dark survival times reduced to only 7 days when exposed to $10^{\circ} \mathrm{C}$. Recovery of maximum quantum yield of fluorescence ( $\mathrm{Fv} / \mathrm{Fm})$ was not significantly impacted by temperature, species or dark exposure length. Recovery rates of $\mathrm{Fv} / \mathrm{Fm}$ ranged from $-5.06 \mathrm{E}-$ $7 \pm 2.71 \mathrm{E}-7 \mathrm{~s}^{-1}$ to $1.36 \mathrm{E}-5 \pm 1.53 \mathrm{E}-5 \mathrm{~s}^{-1}$ for monthly experiments and from $-9.63 \mathrm{E}-7 \pm 7.71 \mathrm{E}-7 \mathrm{~s}^{-1}$ to $2.65 \mathrm{E}-5 \pm 2.97 \mathrm{E}-5 \mathrm{~s}^{-1}$ for weekly experiments. NPQ recovery was greater and more consistent than $\mathrm{Fv} / \mathrm{Fm}$ recovery, ranging between $5.74 \mathrm{E}-7 \pm 8.11 \mathrm{E}-7 \mathrm{~s}^{-1}$ to
\end{abstract}

Electronic supplementary material The online version of this article (doi:10.1007/s00300-011-0961-x) contains supplementary material, which is available to authorized users.

S. Reeves · A. McMinn $(\bowtie) \cdot$ A. Martin Institute of Marine and Antarctic Science, University of Tasmania, Private Bag 129, Hobart, TAS 7001, Australia

e-mail: andrew.mcminn@utas.edu.au
$7.50 \mathrm{E}-3 \pm 7.1 \mathrm{E}-4 \mathrm{~s}^{-1}$. The concentration of chl- $a$ and monosaccharides remained relatively constant in both experiments. These results suggest that there will probably be little effect on Antarctic microalgae with increasing water temperatures during the Antarctic winter.

Keywords Winter - Dark survival Phytoplankton . Sea ice

\section{Introduction}

Sea ice is a defining structural feature of polar marine regions and varies on a number of temporal scales, ranging from hourly to inter-annually (Eicken 1992). Abiotic variations within sea ice have a considerable impact on the spatial heterogeneity of sea ice zones. The temporal and spatial heterogeneity of sea ice combined with the seasonal alternation in incident solar radiation is a key determining factor in the amount of irradiance available for polar photoautotrophs (Lizotte 2001; Thomas and Dieckmann 2002; Knox 2006). As a result, primary production and biomass in polar regions exhibit a marked seasonal pattern-with short periods of intense production in the summer followed by long periods of limited production.

In contrast to highly variable irradiance, sea-water temperatures are relatively stable with annual fluctuations rarely exceeding $3^{\circ} \mathrm{C}$, and sometimes less than $0.5^{\circ} \mathrm{C}$. The Antarctic marine environment is thus one of the most thermally stable on earth, and in all likelihood, it has been this way for the past 10 million years (Peck 2005). Although there appears to be little evidence yet that the waters around Antarctica have warmed significantly, models predict that global water temperatures will rise on average by $2^{\circ} \mathrm{C}$ by 2100 (Peck 2005). There has already been a marked 
warming on the western side of the Antarctic Peninsula, with the observed increase being as large as any yet seen globally (Turner et al. 2005). Following the long period of sea-water temperature stability, it is possible that even a small change in temperature could have a significant impact on photosynthetic organisms such as sea ice algae, phytoplankton, benthic microalgae and macroalgae. Although warming is likely to continue, the annual light and dark cycles will remain unchanged and polar organisms will have to spend the polar night at increasingly elevated temperatures. These changes are likely to impact photoautotrophic survival and primary productivity. Sea ice microbial communities, which can have a biomass over $300 \mathrm{mg}$ chl $-a \mathrm{~m}^{-2}$ (Palmisano and Sullivan 1983; Trenerry et al. 2002), currently play a pivotal role in Antarctic marine ecosystems, forming the energy base of the marine food web for up to 10 months of the year and providing an inoculum for spring algal blooms (Bunt and Lee 1972; Andreoli et al. 2000; Baldisserotto et al. 2005a).

The photosynthetic apparatus of photoautotrophic organisms rapidly responds to environmental alterations through acclimatory processes involving a succession of morpho-physiological changes. These include modifications to the structural and functional organisation of the thylakoid membranes and variations in the relationship between the antennae and reaction centres of the photosystems (PS). Thylakoid structure and function are influenced by the relative proportion of light-harvesting pigments (i.e. chlorophylls and carotenoids), photosystem II (PSII) and photosystem I (PSI) reaction centres and antennae, electron carriers, and ATP synthetase (Demmig-Adams and Adams 1992; Baldisserotto et al. 2005a, b; Morgan-Kiss et al. 2006). Plants respond to high, low or no light by making changes to their pigment composition, their photophysiology and by making structural changes to their chloroplasts (McConville 1985; Demmig-Adams and Adams 1992; Lüder et al. 2001, 2002; Baldisserotto et al. 2005a, b; Morgan-Kiss et al. 2006). Both higher and lower light levels can affect the growth and survival of microalgae. High light can result in the reduction in photosynthetic efficiency and photosynthetic rates through photoinhibition. Processes such as fluorescence and non-photochemical quenching (NPQ) are able to reduce this photoinhibitive damage caused by excess energy absorption (Demmig-Adams and Adams 1992). Low or no light results in the reduction in photosynthetic rates, alterations in behaviour, metabolism and often the re-absorption of photosynthetic organelles and pigments.

Temperature impacts the physiology of photoautotrophic organisms through various effects on membranes, enzymes and metabolic functioning (Morgan-Kiss et al. 2006). A major adaptation of metabolic function influencing growth and photosynthesis at low temperatures is the maintenance of membrane fluidity (Thomas and Dieckmann 2002; Morgan-
Kiss et al. 2006). The majority of protein components associated with the photosynthetic apparatus are anchored in the photosynthetic membranes via specific lipid species, the galactolipids (Morgan-Kiss et al. 2006). The light-dependent stage of photosynthesis predominantly occurs across membranes; thus, the efficiency of these reactions is significantly impacted by alterations in temperature (Morgan-Kiss et al. 2002, 2006; Thomas and Dieckmann 2002). Increasing temperatures will cause elevated chemical reaction rates, while a reduction in temperature will generally result in reduced reaction rates. Similarly, the rate of biochemical reactions associated with photosynthesis, such as carboxylation, is impacted by alterations in temperature (Davison 1991; Morgan-Kiss et al. 2006). Altered light and temperature regimes are thus likely to influence both the photophysiological and physiological functioning.

However, the dark survival capacity of some phytoplankton species is considerable. Maximum survival times of up to 96 months have been reported for some diatom species and as much as 112 months for some dinoflagellate species (Antia and Cheng 1970; Antia 1976; Doucette and Fryxell 1983; Peters 1996; Peters and Thomas 1996). Previous studies on dark survival have focussed on the effects on growth and structural alterations at the cellular level (Antia and Cheng 1970; Antia 1976; Peters and Thomas 1996; Baldisserotto et al. 2005a, b; Ferroni et al. 2007; Wulff et al. 2008). These studies suggest that photosynthetic organisms survive winter by preferential degradation of the photosynthetic apparatus in concert with other survival mechanisms. Survival mechanisms range from stasis through resting cell and cyst formation, alteration in trophic mode, utilisation of stored reserves and reduced metabolic rates.

The aim of this study is to determine the impact of elevated temperatures on the dark survival of three species of diatoms from the Antarctic sea ice ecosystem, Fragilariopsis cylindrus (Grunow) Krieger, Thalassiosira antarctica Comber and Entomoneis kjellmanii.

\section{Materials and methods}

\section{Experimental set-up}

Axenic cultures of Fragilariopsis cylindrus, Thalassiosira antarctica and Entomoneis kjellmanii isolated from sea ice of the Mertz Glacier region of the Southern Ocean (Pankowski and McMinn 2009) are maintained in the Antarctic Culture Facility at the University of Tasmania. Batch cultures of each species were incubated in f2 media (Guillard 1975) under constant light conditions $\left(41 \pm 13 \mu \mathrm{mol}\right.$ photons $\left.\mathrm{m}^{-2} \mathrm{~s}^{-1}\right)$ at $2^{\circ} \mathrm{C} \pm 0.5^{\circ} \mathrm{C}$ for approximately 2 weeks. Cultures were transferred into 
25-ml scintillation vials for experimental manipulation during the log growth phase to ensure sufficient nutrients remained in the culture during transfer and maintenance in darkness. Then, $20 \mathrm{ml}$ of each of the three cultures was transferred into the sterile scintillation vials, wrapped in aluminium foil and maintained in darkness at three different temperatures; $-2^{\circ} \mathrm{C} \pm 0.5^{\circ} \mathrm{C}, 4^{\circ} \mathrm{C} \pm 0.5^{\circ} \mathrm{C}$ and $10^{\circ} \mathrm{C} \pm$ $1^{\circ} \mathrm{C}$. The $-2^{\circ} \mathrm{C}$ incubation was maintained in a WiseCircu 20-L water bath (Daihan Scientific, Seoul, Korea) using a $12.5 \%$ water/methanol mix to lower the freezing point, and the 4 and $10^{\circ} \mathrm{C}$ incubations used Lauda refrigerated circulating water baths (Lauda, Lauda-Königshofen, Germany). Experimental manipulation was undertaken in darkness using a weak red illuminating light to limit exposure to light. Two experiments were run using different temporal sampling scales, monthly and weekly; the monthly sampling interval experiment was run first. Six vials from each species and temperature combination were removed and analysed at each measurement time (i.e. 54 vials for each sampling event); three for chl- $a$ biomass and PAM analysis (same samples used) and three for carbohydrate analysis. The PAM analyses (non-destructive), which did not affect the chlorophyll analyses, were conducted immediately prior to the latter analyses on the same samples. No samples were reused on subsequent sampling events.

\section{Fluorescence measurements}

A WaterPAM(Walz GmbH, Effeltrich, Germany) was used for all pulse amplitude modulation (PAM) fluorescence measurements. PAM methodology followed Ralph and Gademann (2005), Ralph et al. (2005) and McMinn and Hattori (2006). PAM fluorometers are able to measure maximum quantum yield $(\mathrm{Fv} / \mathrm{Fm})$ and relative electron transfer rate (rETR) of photosystem II (PSII) and to quantify levels of photochemical (PQ) and non-photochemical (NPQ) quenching. Using rapid light curves (RLC), it is also possible to measure the maximum relative electron transport rate (rETRmax), the photosynthetic efficiency $(\alpha)$ and the photoadaptive state $\left(\mathrm{E}_{\mathrm{k}}\right)$. Measurements followed a preset RLC program controlled by WinControl software (Walz, Effeltrich, Germany) on a PAMControl unit (Walz, Effeltrich, Germany). Actinic light levels used were 0, 27, 38, 54, 82, 120, 186, 277 and $395 \mu$ mol photons $\mathrm{m}^{-2} \mathrm{~s}^{-1}$ and the exposure time at each actinic light level was $10 \mathrm{~s}$. To determine photosynthetic efficiency $(\alpha)$ and rETRmax (Ralph and Gademann 2005), the RLC data were fitted to the double exponential decay function of (Platt et al. 1980) using a Marquardt-Levenberg regression algorithm:

$P=\operatorname{Ps}\left(1-e^{-(\alpha \mathrm{Ed} / \mathrm{Ps})} e^{-(\beta \mathrm{Ed} / \mathrm{Ps})}\right)$

In the absence of photoinhibition $(\beta=0)$, the function becomes an asymptotic maximum rETR value (Jasby and Platt 1976), and Eq. 1 can be simplified to:
$P=\operatorname{Pm}\left(1-e^{-(\alpha \mathrm{Ed} / \mathrm{Pm})}\right)$

where $P$ is the rETR at a given irradiance, Ps is defined as the maximum potential rETR in the absence of photoinhibitory processes, $\mathrm{Pm}$ is the rETR at saturating light, $\alpha$ is the initial slope of the RLC before the onset of saturation, Ed is the downwelling irradiance $(400-700 \mathrm{~nm})$ and $\mathrm{b}$ characterises the slope of the RLC beyond the onset of photoinhibition (Ralph et al. 2005).

When the quantum yield of a sample fell to 0.1 following a treatment, it was considered to be inactive or dead and these cultures were then allowed to recover under low actinic light (PAM actinic light setting 1, $27 \mu \mathrm{mol}$ photons $\mathrm{m}^{-2} \mathrm{~s}^{-1}$ ) in a WaterPAM for $12 \mathrm{~h}$ with a saturation pulse every $30 \mathrm{~min}$ to measure $\mathrm{Fv} / \mathrm{Fm}$. Recovery rates of the three replicates were measured in temperature-controlled environments at the temperature of the incubations. The rate of recovery was determined using a non-linear regression to the function

$\Phi_{t}=\Phi_{I}+\left(\Phi_{M}-\Phi_{I}\right)\left(1-e^{-\mathrm{rt}}\right)$

where $\Phi_{t}$ is the value of $\mathrm{Fv} / \mathrm{Fm}$ at time $t(\mathrm{~s}), \Phi_{I}$ is the initial value of $\mathrm{Fv} / \mathrm{Fm}$ before recovery readings have commenced and $\Phi_{M}$ is the maximum value of $\mathrm{Fv} / \mathrm{Fm}$ at $T=0$ or the beginning of the experiment. This calculation of $r$, the rate of recovery, follows Oliver et al. (2003) and assumes that the rate of recovery is dependent on the degree of damage (Kok 1956; Oliver et al. 2003; McMinn and Hattori 2006).

\section{Chlorophyll $a$ concentration}

Chlorophyll $a$ measurement followed the acidification method (Holm-Hansen et al. 1965) on a 'Turner Designs' 10AU fluorometer (Turner Designs, Sunnyvale, USA). The triplicate chlorophyll samples were filtered from the scintillation vials (i.e. $20 \mathrm{ml}$ filtered) onto 47-mm Advantec GF-75 filter (Toyo Roshi Kaisha, Ltd, Japan) under a low-pressure vacuum filtration unit, the filter paper was folded and wrapped in aluminium foil and stored in a laboratory freezer held at $-80^{\circ} \mathrm{C}$. Samples were extracted by adding $10 \mathrm{ml}$ of $100 \%$ methanol to a centrifuge tube containing the filter paper. The samples were then allowed to extract for $24 \mathrm{~h}$ at $4^{\circ} \mathrm{C}$ in darkness. The fluorescence of the extract was then measured with the fluorometer and fluorescence readings converted to chl- $a$ concentrations (Holm-Hansen and Riemann 1978).

Monosaccharides analysis

Triplicate 20-ml samples were filtered onto 47-mm Whatman GF/F filters under gentle vacuum pressure $(<200$ $\mathrm{mm} \mathrm{Hg}$ ) and stored at $-80^{\circ} \mathrm{C}$ until analysis. Filters were extracted with 50\% methanol and 50\% chloroform for $6 \mathrm{~h}$ and dried to ensure removal of contaminants. Each filter was 
subsequently sealed in a glass test tube with $10 \mathrm{ml}$ of Milli$\mathrm{Q}$ water and placed in a water bath for $1 \mathrm{~h}$ at $80^{\circ} \mathrm{C}$. Following extraction, the tubes were cooled and then centrifuged for $5 \mathrm{~min}$ at $715 \times \mathrm{g}$ (van Oijen 2004). The concentration of water-extractable, dissolved monosaccharides was estimated using the 2,4,6-tri pyridyl-s-triazine (TPTZ) spectroscopic method developed by Myklestad et al. (1997) and modified by Hung and Santschi (2001). Briefly, the extracted carbohydrates were subjected to an oxidation reaction at alkaline $\mathrm{pH}$, during which $\mathrm{Fe}^{3+}$ is reduced to $\mathrm{Fe}^{2+}$. The $\mathrm{Fe}^{2+}$ was then determined colorimetrically at $595 \mathrm{~nm}$ after condensation with the chromogen TPTZ to produce a violet-coloured $\mathrm{Fe}(\mathrm{TPTZ})_{2}^{2+}$ complex. The monosaccharide concentration was measured against a calibration curve made from D-glucose. Due to the high light sensitivity of the analytical reagents, reactions were carried out either in the dark or with red light (van Oijen 2004).

\section{Statistics}

All parameters were tested for significance between $T=0$ values and final values using a 3-way ANOVA in the statistical package $\mathrm{R}$ (version 2.11.1). End values in the monthly experiments were determined as the last point where all species could be compared, i.e. the last time at which all species were present. Significance was also tested for temperature impacts on final values of parameters for each species with 1-way ANOVA. Assumptions of ANOVA were achieved by standard checking for normality and homogeneity of variances by plotting diagnostic plots. Carbohydrate data from the experiments sampled at weekly intervals were analysed using general linear models in Systat (version 13) with temperature and time as independent variables. The monthly data were analysed using 1-way ANOVA with time as the independent variable, and the data were subsequently pooled prior to testing for a difference between temperature treatments for each species using 1-way ANOVA and a post hoc Tukey test. Throughout these experiments, $n=3$ and significance was tested at $P<0.05$.

\section{Results}

Chlorophyll $a$ concentration

Monthly Sampling: There was a rise in chl- $a$ between d-0 and d-30 in F. cylindrus at all three temperatures with the greatest rise occurring at $-2^{\circ} \mathrm{C}$ (Fig. 1a). A similar rise was also observed in $T$. antarctica, although only in the $10^{\circ} \mathrm{C}$ and $-2^{\circ} \mathrm{C}$ treatments. In the $4^{\circ} \mathrm{C}$ treatment, chl- $a$ declined continuously throughout the experiment (Fig. 1b). Chl- $a$ of E. kjellmanii initially rose between d-0 and $\mathrm{d}-30$ in both $-2^{\circ} \mathrm{C}$ and $4^{\circ} \mathrm{C}$ treatments but then declined. Chl- $a$ in the $10^{\circ} \mathrm{C}$ treatment declined (Fig. 1c). There were significant differences between the beginning and the end values of chl- $a$ across all temperature treatments and species (3-way ANOVA, see electronic supplementary material). Comparison of $\mathrm{d}-30$ values using one-way ANOVAs showed significant differences between $F$. cylindrus and E. kjellmanii $(P<0.05)$. Multiple comparisons suggest that the $-2^{\circ} \mathrm{C}$ treatment of $F$. cylindrus was significantly different from the other temperature treatments, while the $10^{\circ} \mathrm{C}$ treatment of E. kjellmanii was significantly different from the two cooler treatments.

Weekly Sampling: Few clear trends in chl- $a$ concentration were seen in any species in this experiment. Chl- $a$ levels in $F$. cylindrus remained approximately constant with no temperature treatment showing any significant difference (Fig. 1d). While there was a fall in the 4 and $-2^{\circ} \mathrm{C}$ treatments of T. antarctica, there was a small rise in the $10^{\circ} \mathrm{C}$ treatment (Fig. 1e). There was an increase in the chl- $a$ concentration of the -2 and $4^{\circ} \mathrm{C}$ treatments of E. kjellmanii, but there was a decline in the $10^{\circ} \mathrm{C}$ treatment (Fig. 1f). Comparing end values for each species and temperature treatment with a 3-way ANOVA showed that there were significant differences. In particular, end values of chl- $a$ for $F$. cylindrus and $T$. antarctica were not significantly different. Only E. kjellmanii showed any significant difference between temperature treatments with multiple comparisons, suggesting that the $10^{\circ} \mathrm{C}$ treatment were significantly different from the -2 and $4^{\circ} \mathrm{C}$ treatments.

Maximum quantum yield

Monthly Sampling: $\mathrm{Fv} / \mathrm{Fm}$ of $F$. cylindrus steadily decreased with time in all temperature treatments (Fig. 2a). $\mathrm{Fv} / \mathrm{Fm}$ in the 10 and $-2^{\circ} \mathrm{C}$ treatments of $T$. antarctica dropped to 0.00 between $\mathrm{d}-0$ and $\mathrm{d}-30$ but in the $4^{\circ} \mathrm{C}$ treatment finished at 0.14 (Fig. 2b). Fv/Fm of the $4^{\circ} \mathrm{C}$ E. kjellmanii treatment increased to d-30, while the values of the two other temperature treatments declined (Fig. 2c). There was a significant difference between the $\mathrm{Fv} / \mathrm{Fm}$ values of the d-30 temperature treatments of $F$. cylindrus and E. kjellmanii. Multiple comparisons between all species at all temperatures showed that the 4 and $10^{\circ} \mathrm{C}$ temperatures treatments of $F$. cylindrus were significantly different. All temperature treatments of E. kjellmanii at d-30 were significantly different from each other. Differences between beginning and end values across all species and temperature treatments were also significant.

Weekly Sampling: $\mathrm{Fv} / \mathrm{Fm}$ values of all species and with one exception (E. kjellmanii at $\left.4^{\circ} \mathrm{C}\right)$ at all temperatures fell throughout the experimental period (Fig. 2d-f). In F. cylindrus, $\mathrm{Fv} / \mathrm{Fm}$ values fell to 0.00 by the end of the experiment at all temperatures. The $10^{\circ} \mathrm{C}$ treatment declined most rapidly, followed by 4 and $-2^{\circ} \mathrm{C}$ (Fig. 2d). 
Fig. 1 Mean Chl- $a$ for all species and experiments $(n=3)$, errors are standard deviations
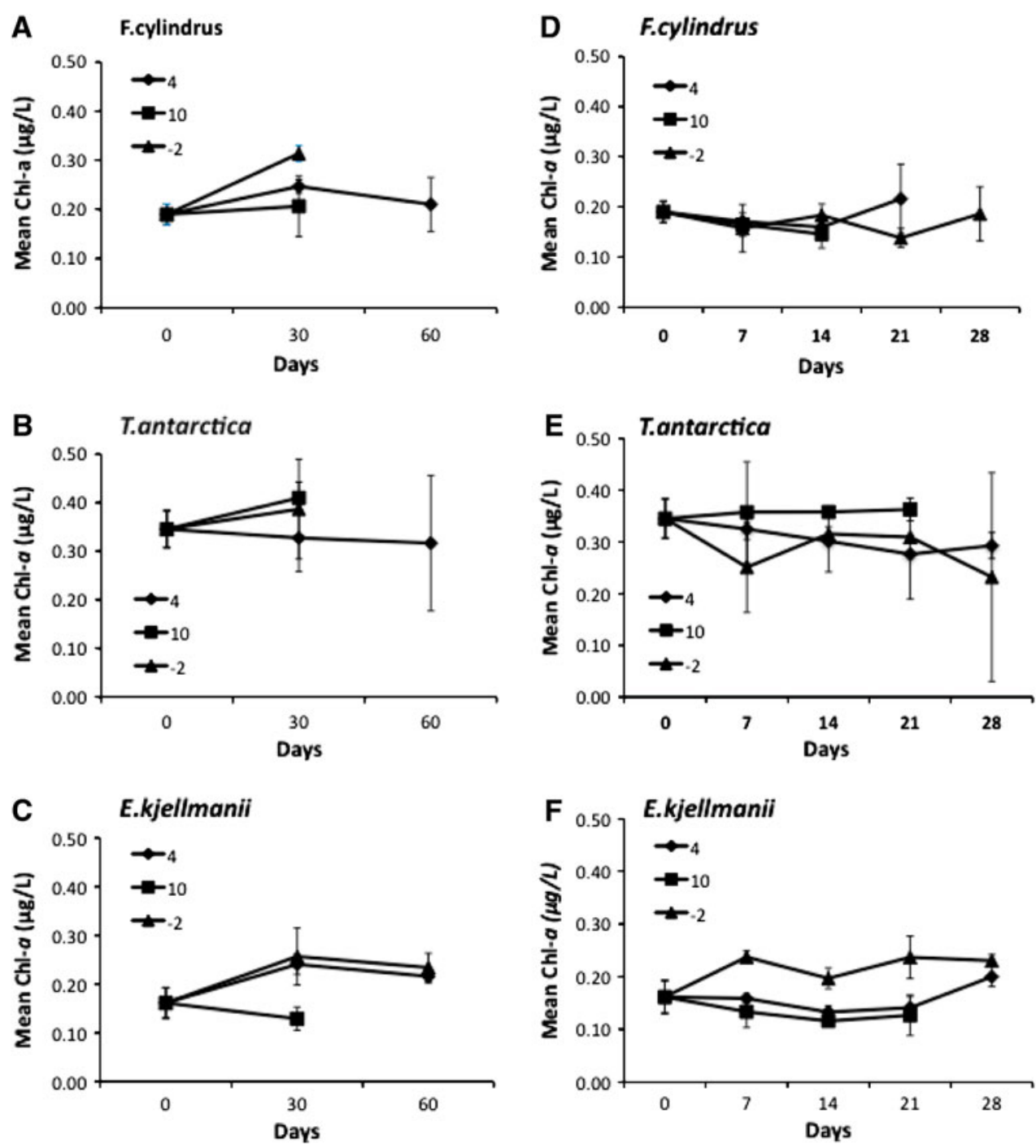

T. antarctica had a similar response to $F$. cylindrus, although there was an initial increase in the $-2^{\circ} \mathrm{C}$ treatment (Fig. 2e). While the Fv/Fm values of the 10 and $-2{ }^{\circ} \mathrm{C}$ treatments of E. kjellmanii declined during the course of the experiment (Fig. $2 \mathrm{~F}$ ), the $4^{\circ} \mathrm{C}$ treatment rose to above 0.60. A 3-way ANOVA examining the beginning and end values of Fv/Fm across all species and temperature treatments found all the terms were significant. One-way ANOVAs showed that only the final Fv/Fm values of the E. kjellmanii temperature treatments were significantly different from each other.

\section{Relative ETRmax}

Monthly Sampling: F. cylindrus and T. antarctica showed similar trends. In both, there was a rapid decline to d-30 in both the 10 and $-2^{\circ} \mathrm{C}$ treatments, while in the $4^{\circ} \mathrm{C}$ treatment, there was a smaller decline (Fig. 3a, b). E. kjellmanii had a similar decline in the 10 and $-2^{\circ} \mathrm{C}$ treatments
(Fig. 3c) but the $4^{\circ} \mathrm{C}$ treatment initially declined at a slower rate. At d-30, only E. kjellmanii showed significant differences between any of the temperature treatments with the $10^{\circ} \mathrm{C}$ treatment being significantly different to the $-2^{\circ} \mathrm{C}$ treatment. There was no significant difference between the 4 and $-2^{\circ} \mathrm{C}$ treatments.

Weekly Sampling: The rETRmax of all three species declined throughout the experiment (Fig. 3 d-f). T. antarctica had the largest drop in rETRmax (Fig. 3b). During the $10^{\circ} \mathrm{C}$ treatment, rETRmax dropped from $14.01 \pm 1.38$ to $0.71 \pm 0.42$ after only seven days, while in the other two treatment temperatures, it exhibited a more gradual decline. $F$. cylindrus had a more gradual decline with similar values throughout the experiment for all three temperatures (Fig. 3d). A similar pattern was seen in E. kjellmanii with similar reductions in rETRmax in the -2 and $10^{\circ} \mathrm{C}$ treatments. In the $4^{\circ} \mathrm{C}$ treatment, however, rETRmax remained steady throughout the entire experiment. There were significant differences between the beginning and the end 
Fig. 2 Mean maximum quantum yield (Fv/Fm) for all species, temperature treatments and experiments $(n=3)$, errors are standard deviations
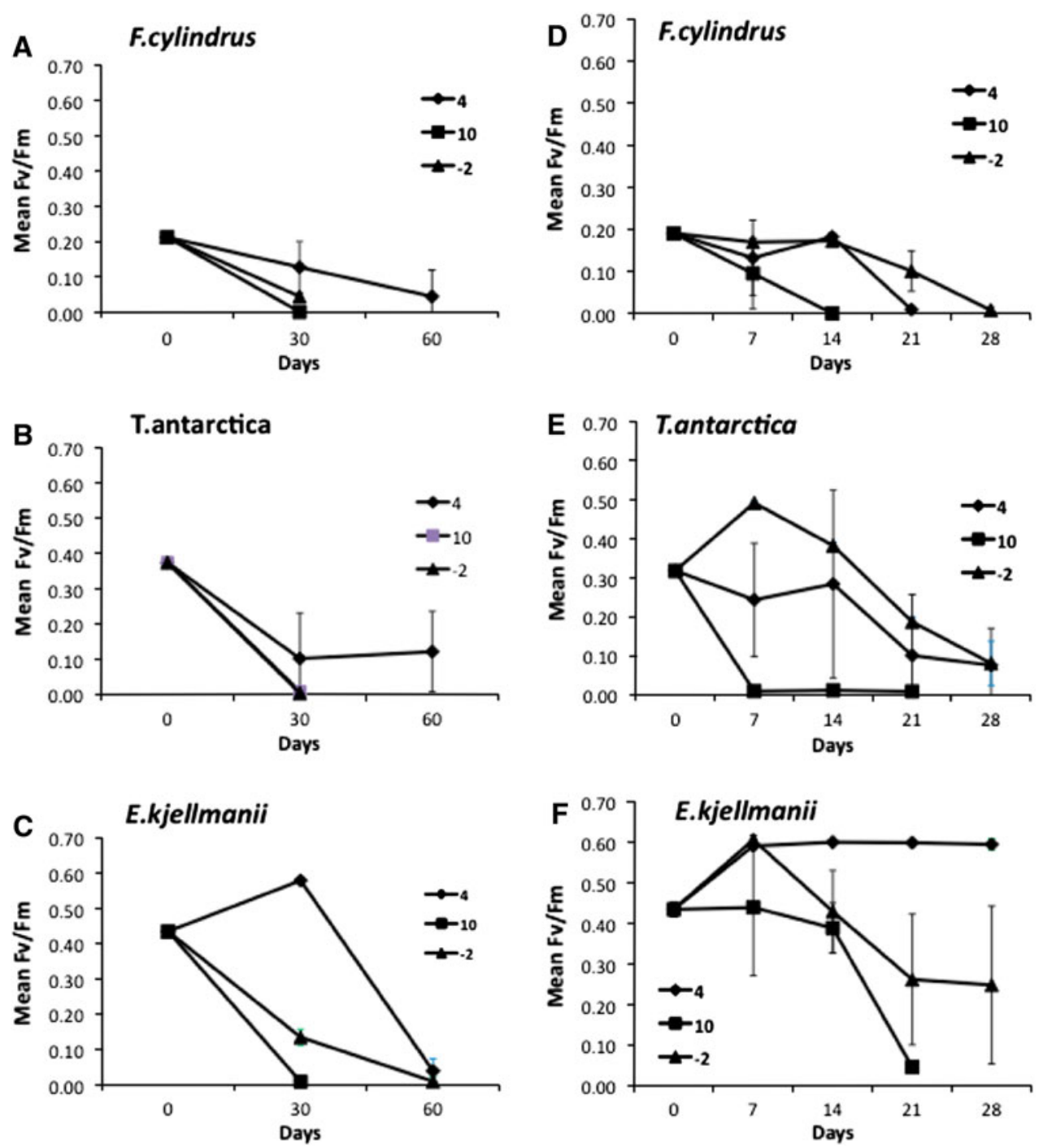

values of rETRmax across all temperature treatments and species (3-way ANOVA). However, only the rETRmax values of the E. kjellmanii treatments were significantly different from other final values.

\section{Maximum NPQ}

Monthly Sampling: Similar responses were observed in all species. The NPQ of all species at all temperatures fell by d-60. The $10^{\circ} \mathrm{C}$ treatment of all species fell sharply in the first 30 days (Fig. 4a-c. The greatest differentiation between temperature treatments occurred in $F$. cylindrus (Fig. 4a) with much greater values of maximum NPQ at $4^{\circ} \mathrm{C}$ than in the -2 or $10^{\circ} \mathrm{C}$ treatments. There were significant differences between the beginning and the end values of maximum NPQ across all temperature treatments and species (3-way ANOVA). Analysis of end values for single species maximum NPQ for experiment 2 (1-way ANOVA) yielded significant differences for $F$. cylindrus and E. kjellmanii. The $4^{\circ} \mathrm{C}$ treatment of $F$. cylindrus and the $-2^{\circ} \mathrm{C}$ treatment of $E$. kjellmanii were significantly different from the other temperature treatments.

Weekly Sampling: Maximal values of NPQ were consistently higher in the $-2^{\circ} \mathrm{C}$ treatment than in the other temperature treatments (Fig. 4d-f). There was a sharp and immediate drop in maximum NPQ of all species in the $10^{\circ} \mathrm{C}$ treatment. The maximum NPQ values of the two cooler temperature treatments declined later, first in the $4^{\circ} \mathrm{C}$ treatment after $\mathrm{d}-14$ and then in the $-2^{\circ} \mathrm{C}$ treatment, after d-21. End of experiment maximum NPQ values were only significantly different for E. kjellmanii with Tukey's pairwise contrasts suggesting only the $4^{\circ} \mathrm{C}$ treatment significantly differed from the other treatments.

\section{Recovery}

Maximum quantum yield: The recovery rates of $\mathrm{Fv} / \mathrm{Fm}$ after dark exposure in the monthly sampling experiment 
Fig. 3 Mean ETRmax for all species, temperatures and experiments $(n=3)$, errors are standard deviations
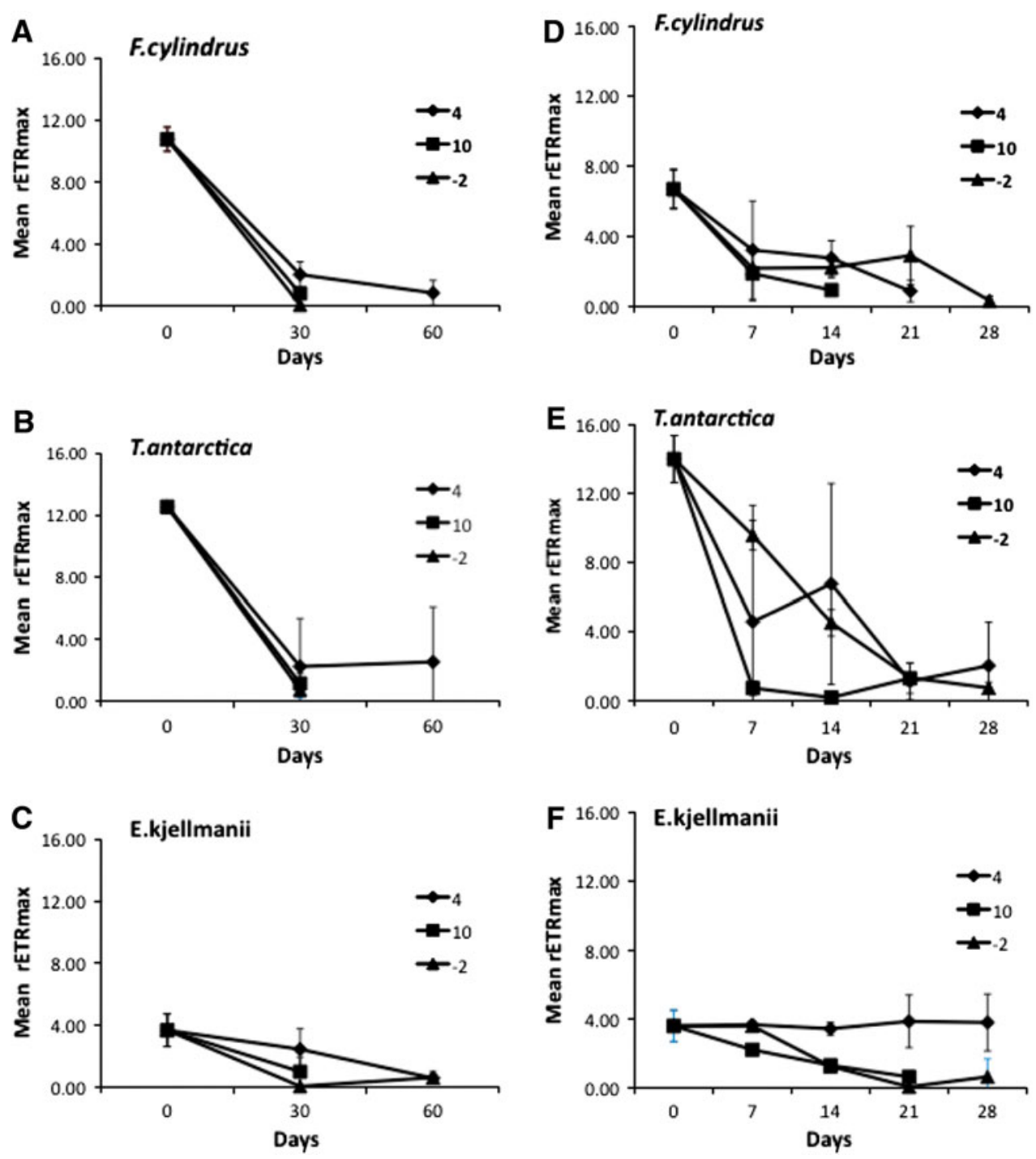

did not differ significantly with temperature or species. However, $F$. cylindrus grown at $10^{\circ} \mathrm{C}$ had the fastest recovery rate $(1.36 \mathrm{E}-5 \pm 1.53 \mathrm{E}-5)$ with the other treatment temperatures of this species failing to recover. The fastest recovery rate of $T$. antarctica was at $-2^{\circ} \mathrm{C}(1.22 \mathrm{E}-$ $6 \pm 2.82 \mathrm{E}-6)$ with the 4 and $10^{\circ} \mathrm{C}$ treatments recovering at marginally slower rates, $7.38 \mathrm{E}-7 \pm 2.06 \mathrm{E}-7$ and $5.16 \mathrm{E}-7 \pm 5.4 \mathrm{E}-8$, respectively. E. kjellmanii had its slowest recovery rate at $-2^{\circ} \mathrm{C}(3.92 \mathrm{E}-7 \pm 2.71 \mathrm{E}-7)$ with 4 and $10^{\circ} \mathrm{C}$ treatments having considerably higher recovery rates $\left(4^{\circ} \mathrm{C}: \quad 1.33 \mathrm{E}-5 \pm 6.54 \mathrm{E}-7 ; \quad 10^{\circ} \mathrm{C}: \quad 3.21 \mathrm{E}-\right.$ $6 \pm 1.2 \mathrm{E}-8)$. With the exception of $T$. antarctica at $-2^{\circ} \mathrm{C}$, all species and temperature treatments recovered from the 30-day dark incubation.

$N P Q$ Recovery: NPQ recovered at a faster rate and to a greater extent than Fv/Fm. E. kjellmanii had a faster rate of recovery than either $T$. antarctica or $F$. cylindrus across all temperature treatments with recovery rates ranging between $3.79 \mathrm{E}-4$ and $7.59 \mathrm{E}-3$. F. cylindrus had the lowest recovery rate, $9.69 \mathrm{E}-6$. There was an order of magnitude difference between E. kjellmanii and T. antarctica NPQ recovery rates. Similarly, NPQ recovery rates of $T$. antarctica were an order of magnitude greater than F. cylindrus.

Carbohydrates

Monthly Sampling: The concentration of water-extractable monosaccharides remained relatively constant during the course of the experiment $\left(\sim 3.0 \mu \mathrm{mol} \mathrm{C} \mathrm{l}^{-1}\right)$, and there were no significant differences with respect to incubation period $(P>0.05$ for each species, Fig. $5 \mathrm{a}-\mathrm{c})$. For $T$. antarctica and $F$. cylindrus, there was no difference between incubation temperatures, but for E. kjellmanii, the concentration of monosaccharides was higher after 30 days at $4^{\circ} \mathrm{C}$ compared to either the $10^{\circ} \mathrm{C}(P=0.032$, Tukey post 
Fig. 4 Mean maximum NPQ for all species, temperatures and experiments $(n=3)$, errors are standard deviations
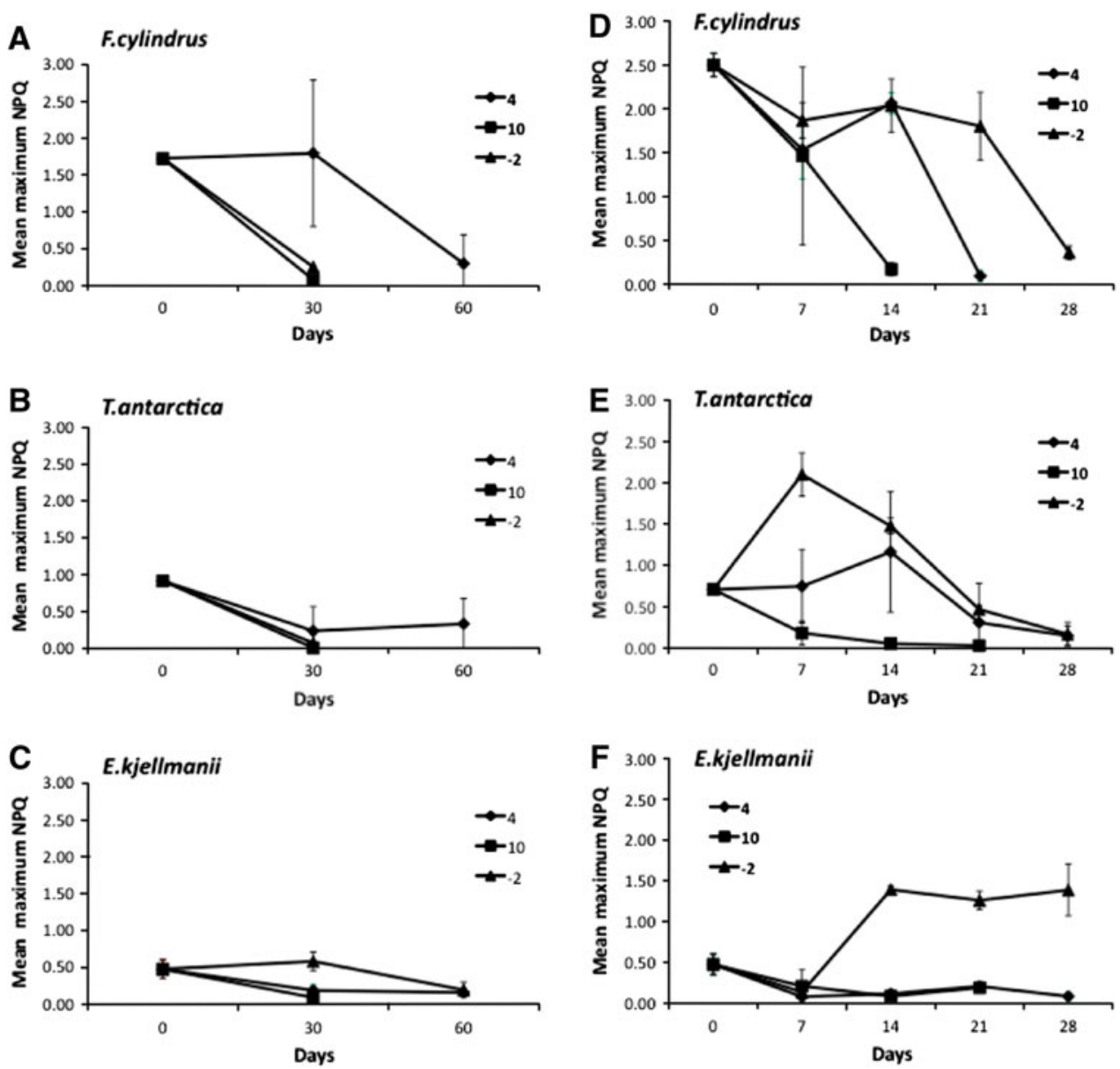

hoc test $)$ or $-2^{\circ} \mathrm{C}(P=0.035$, Tukey post hoc test $)$ incubation regimes.

Weekly Sampling: The maximum concentration of water-extractable monosaccharides was recorded on d-0 for T. antarctica and E. kjellmanii, and this was correlated with the highest concentration of chl- $a$ (Fig. 5d-f). The monosaccharide content of $F$. cylindrus and $T$. antarctica varied between $2.75 \pm 0.25$ and $1.23 \pm 0.12 \mu \mathrm{mol} \mathrm{C} 1^{-1}$ and $3.02 \pm 0.13$ and $1.5 \pm 0.71 \mu \mathrm{mol} \mathrm{C} \mathrm{^{-1 }}$, respectively, over the course of the experiment, but there was no significant difference between time points or variation among temperature treatments. For E. kjellmanii, the concentration of monosaccharides decreased significantly from $10.88 \pm 1.77 \mu \mathrm{mol} \mathrm{C}^{-1}$ on $\mathrm{d}-0$ to $<6.0 \mu \mathrm{m}$ mol C $1^{-1}$ on d-7 for each temperature, but the subsequent measurements for each temperature treatment on days 14,21 and 28 were not significantly different $(P>0.05)$. Incubation temperature had a marginal effect on the size of the carbohydrate pool, and the concentration of dissolved monosaccharides was somewhat higher at $-2^{\circ} \mathrm{C}$ compared to either the 4 or $10^{\circ} \mathrm{C}$ treatments $(P=0.06)$.

\section{Discussion}

The term 'darkness-survival' was first used by Antia (1976) to define the retention of viability in algae without growth during exposure to darkness. Antia (1976) progressively prolonged the period of incubation of microalgal cultures by weekly increments until algal viability was completely lost. Viability retention was determined by placing the dark-exposed cultures into continuous light at $20^{\circ} \mathrm{C}$ and observing the resumption or failure of autotrophic growth. A similar procedure was followed by Peters (1996) and Peters and Thomas (1996) where viability was examined by exposing subsamples to the growth conditions that existed prior to dark exposure.

Considering the range of temperatures used in this study, it is perhaps surprising that a greater difference in survival and recovery rates between the cooler temperatures $(-2$ and $4^{\circ} \mathrm{C}$ ) and the $10^{\circ} \mathrm{C}$ treatment was not apparent. A number of studies have reported that polar microalgal species are adapted to low temperatures with maximum photosynthetic rates between 4 and $7^{\circ} \mathrm{C}$ (Oeltjen et al. 2002; Mock and Hoch 2005). Several species also exhibit 

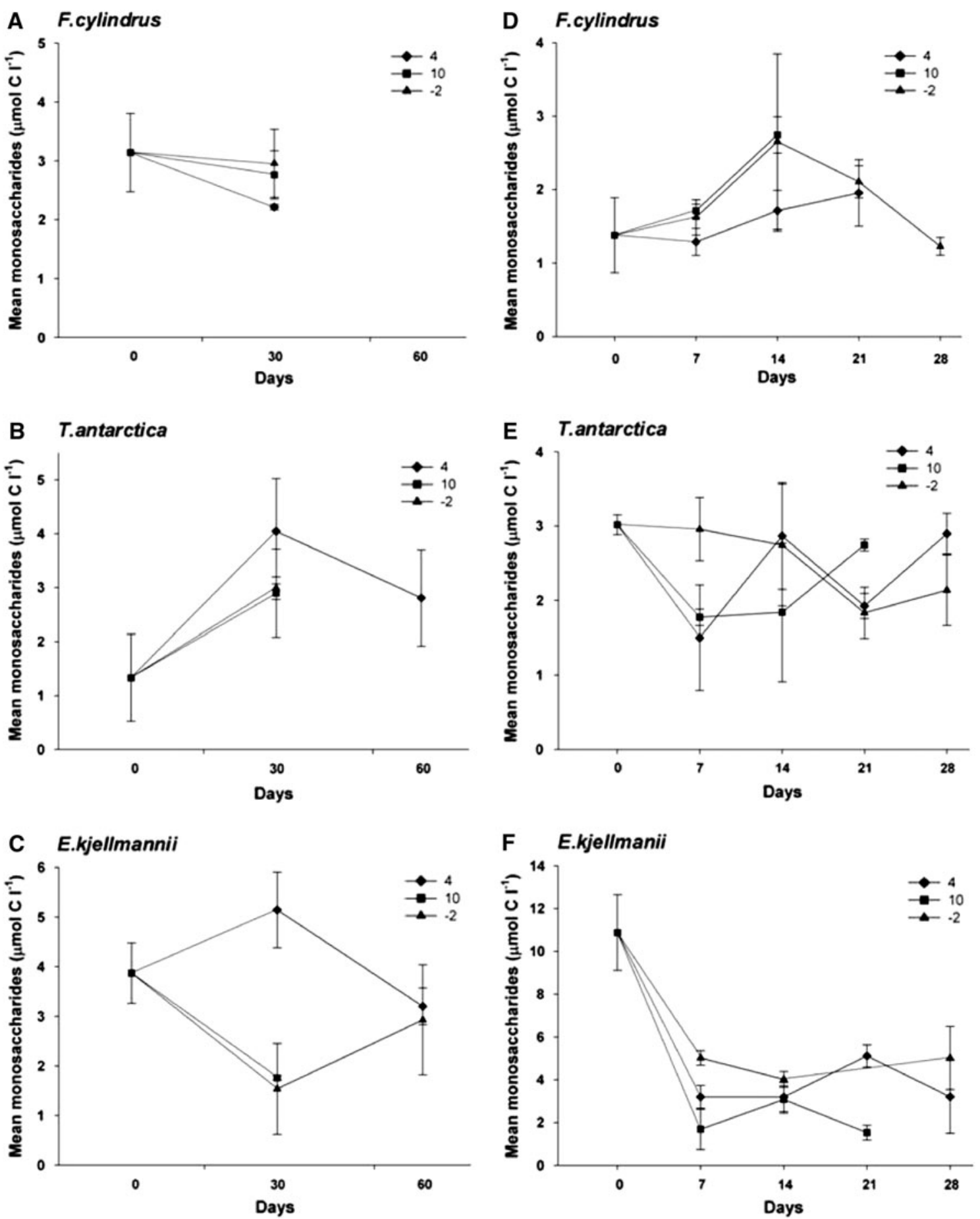

Fig. 5 Mean monosaccharide concentrations for all species, temperatures and experiments $(n=3)$. Data are means \pm SE

maximum rates at around $10^{\circ} \mathrm{C}$ (Kottmeier and Sullivan 1988; Fiala and Oriol 1990). However, some polar species exhibit significant suppression of metabolic activity at low temperatures and many only exhibit temperature limitation above $5^{\circ} \mathrm{C}$ (Palmisano and Sullivan 1982; Palmisano et al. 1985). Thus, the range of temperatures used in the incubations here may not be outside their physiological acclimation limits.

This study found that an Fv/Fm value of less than 0.1 generally indicated inactivity and lack of cell viability as cultures were unable to recover. Consequently, maximum survival times were estimated from the time at which cells 
at any given temperature treatment fell to an $\mathrm{Fv} / \mathrm{Fm}$ value of less than 0.1. If the cultures had an $\mathrm{Fv} / \mathrm{Fm}$ value greater than 0.1 at the end of the experiment, only a minimum survival time could be determined. In the current study, maximum survival times of 60 days were observed for the psychrophile $F$. cylindrus at both -2 and $4{ }^{\circ} \mathrm{C}$ while a maximum value of only 7 days was observed at $10^{\circ} \mathrm{C}$. T. antarctica had minimum survival times of 90 days at both cooler temperatures but a maximum survival time of only 7 days at $10^{\circ} \mathrm{C}$. Peters and Thomas (1996) reported maximum survival times for $T$. antarctica to be $>200$ days, but these values were for the resting stages of $T$. antarctica, while the values reported here are for $T$. antarctica as vegetative cells.

The concentration of chl- $a$ levels remained approximately constant throughout both experiments, although in some instances levels increased during initial dark exposure. This rise in pigment content during the early period of darkness has been widely observed in both microalgae and macroalgae (Peters 1996; Peters and Thomas 1996; Botsford et al. 1997; Lüder et al. 2001, 2002) and allows cells to optimise light-harvesting capacity under reduced light (Lizotte and Sullivan 1992; Falkowski and Raven 2007). A major requirement to survive prolonged dark periods is the maintenance of the photosynthetic apparatus, which is vital for efficient photosynthesis on return to favourable light levels (Peters 1996; Peters and Thomas 1996; Botsford et al. 1997). Importantly, a reduction in chl- $a$ might infer degradation of PSII and PSI reaction centres (Lüder et al. 2002), which was the trend observed in both experiments. It is also possible that cell division in the dark occurred but as cell counts were not undertaken, it is not possible to clarify this possibility with any certainty.

In this study, Fv/Fm was used as an indicator of inactive/'dead' cultures. Fv/Fm provides a robust and easily measured parameter indicating photosynthetic health (Cullen and Davis 2003; Franklin et al. 2009). Various studies have reported values of $\mathrm{Fv} / \mathrm{Fm}$ ranging between 0.1 and 0.65 for natural populations of microalgae; larger values indicating healthy cells, while lower values are indicative of increasing physiological stress (McMinn and Hegseth 2004). McMinn and Hegseth (2004) suggested that $\mathrm{Fv} / \mathrm{Fm}$ values below 0.125 inferred little photosynthetic activity and a senescent state. In addition, Franklin et al. (2009) compared the efficiency of PSII $\left(\mathrm{Fv}^{\prime} / \mathrm{Fm}^{\prime}\right)$ with the proportion of photosynthetically non-functional cells. Their results indicated that an $\mathrm{Fv} / \mathrm{Fm}$ value of 0.1 equates to a $15 \%$ efficiency of PSII, which can be modelled to imply that more than $90 \%$ of cells would be photosynthetically non-functional. Rates of recovery here suggest that an Fv/ Fm value of 0.1 and below is a valid indication of nonviable cultures. In the majority of cases, only those cultures that had an Fv/Fm of above 0.1 at the beginning of the recovery period showed any significant recovery of $\mathrm{Fv} / \mathrm{Fm}$ to values indicating a healthy photosynthetic response at the end.

Initial values of $\mathrm{Fv} / \mathrm{Fm}$ observed at the beginning of the experiments ranged from apparently healthy values of $0.45 \pm 0.02$ for E. kjellmanii (monthly sampling) down to $0.19 \pm 0.01$ for $F$. cylindrus (weekly sampling). In the current study, stock cultures of each culture were established at the same time and simultaneously transferred to vials for experimentation. While cultures were allowed to increase in biomass under the same temperature and light conditions, their differing growth rates meant that they were at different stages of their growth cycle and Fv/Fm values were thus not optimised. Starting some experiments with cultures having lower Fv/Fm values was not ideal and probably explains some of the variable response of $\mathrm{Fv} / \mathrm{Fm}$ between species observed during these experiments. It is also important to consider the role of dead cells in cultures, though, as Franklin et al. (2009) showed, non-functional cells have surprisingly little effect on Fv/Fm. Conversely, high values of $\mathrm{Fv} / \mathrm{Fm}$ cannot be used alone as evidence of low mortality in cultures. In the monthly experiment, there was a significant reduction in $\mathrm{Fv} / \mathrm{Fm}$ throughout the period of dark exposure, regardless of temperature. In both experiments, $\mathrm{Fv} / \mathrm{Fm}$ of the $10^{\circ} \mathrm{C}$ treatment dropped quickly to minimal values, while the values of the two cooler temperature treatments remained higher. It is difficult to determine whether the -2 or $4^{\circ} \mathrm{C}$ treatments performed best as the response varied both between experiments and between species. Sometimes the $-2^{\circ}$ treatment had the highest $\mathrm{Fv} / \mathrm{Fm}$ value, while at other times the $4^{\circ} \mathrm{C}$ treatment of the same species was higher. $F$. cylindrus appeared to have the least tolerance to dark incubation with near 0.0 values at the end of each temperature treatment in each experiment. Results of the weekly interval experiment suggest that the fall in $\mathrm{Fv} / \mathrm{Fm}$ observed in the $10^{\circ} \mathrm{C}$ treatment over 1 month could in fact be an artefact of the sampling interval, as when sampling occurred weekly, the reduction in $\mathrm{Fv} / \mathrm{Fm}$ occurred during the first 7-21 days of the experiment. Wulff et al. (2008) studied the impact of re-exposure to dark-exposed benthic diatoms and observed no impact on $\mathrm{Fv} / \mathrm{Fm}$ after 15 days, while $\mathrm{Fv} / \mathrm{Fm}$ values were reduced by close to half their initial values after 64 days of dark exposure (Wulff et al. 2008). When the macroalgae Palmaria decipiens was exposed to darkness for 6 months to simulate an Antarctic winter, Fv/Fm remained robust during the first 2 months and only diminished significantly after 3-6 months, when it fell to as low as 0.1 (Lüder et al. 2002). These authors also modelled the alteration of light throughout the year and so observed differences that may also be partly due to the effects of acclimation to altering light conditions and which might play a vital role in the capacity for dark survival. Following 
dark exposure, Lüder et al. (2002) also slowly re-illuminated dark-incubated $P$. decipiens over a month, whereas in this current study, we used a short recovery process to examine the result of re-illumination.

Recovery of Fv/Fm following dark exposure showed no consistent patterns with respect to species, temperature or time. However, we suggest that there may be a threshold $\mathrm{Fv} / \mathrm{Fm}$ value below which Antarctica microalgae cannot recover from, or at least not in the observed time period. In most cases, only those cultures that had an $\mathrm{Fv} / \mathrm{Fm}$ value of above 0.1 at the beginning of the recovery period showed any significant recovery of $\mathrm{Fv} / \mathrm{Fm}$ to values indicating a healthy photosynthetic response. Recovery was highly variable with some species showing no or negative recovery rates, i.e. further reductions in $\mathrm{Fv} / \mathrm{Fm}$, regardless of re-exposure to light. Previously, this recovery approach has mostly been used to examine recovery from photoinhibition due to vertical mixing processes, exposure to UV radiation and time of day (Oliver et al. 2003; McMinn and Hattori 2006). Unlike McMinn and Hattori (2006), who used the preset recovery procedure in the WaterPAM, our recovery period was significantly longer (WaterPAM recovery period $10 \mathrm{~min}$ while our recovery period was 12 h). Furthermore, both Oliver et al. (2003) and McMinn and Hattori (2006) used this recovery model to describe recovery from photoinhibition, while this study used it to model recovery from dark exposure. Interestingly, our recovery rates are lower than those reported by McMinn and Hattori (2006) (2.2E -4 to $2.8 \mathrm{E}-2 \mathrm{~s}^{-1}$ ) for sea ice algae from the Okhotsk Sea and by Oliver et al. (2003) $\left(4.3 \mathrm{E}-4\right.$ to $\left.9.1 \mathrm{E}-1 \mathrm{~s}^{-1}\right)$ for freshwater phytoplankton from temperate Australia but it is likely that quite different physiological processes affect recovery from long-term dark exposure and that they operate on quite different timescales.

There was a rapid decline in rETRmax values in all species and temperature treatments in both experiments. In all treatments, the greatest decline and lowest values of rETRmax occurred in the $10^{\circ} \mathrm{C}$ treatments. Furthermore, results from the weekly time interval experiment suggest that the decline mostly occurred in the first 1-2 weeks of dark exposure. When significant differences were present between treatments, it was always between one or both of the cooler temperature treatments, $-2^{\circ} \mathrm{C}$ and $4^{\circ} \mathrm{C}$, and the $10^{\circ} \mathrm{C}$ treatment. Wulff et al. (2008) also found that rETRmax of dark-exposed benthic diatoms dropped by over half of initial values following 64 days in darkness. Working with the macroalgae $P$. decipiens, Lüder et al. (2001) found that after a period of darkness replicating an Antarctic winter, rETRmax initially remained stable for the first 2 months but during the third month, it began to fall, dropping to values close to 0.0 by 6 months. The reduction in rETRmax was used to infer the onset of degradation of the photosynthetic apparatus. The photosynthetic process is one of the most thermo-sensitive functions in higher plants, although the response to temperature is thought to be dependent on the amount of light available (Gunnar 1983; Davison 1991; Oquist and Huner 2003). Both Ralph et al. (2005) and Meiners et al. (2009) have shown that rETRmax is temperature dependent with higher values at warmer temperatures and lower values at cooler temperatures. No studies have examined the impact of temperature on photosynthesis during dark exposure, and it appears that the warmer temperatures cause an exacerbated impact on the operation of the photosynthetic apparatus due to increased rates of degradation.

The non-photochemical quenching (NPQ) parameter describes the extent of non-photochemical dissipation of energy. The definition of NPQ assumes the presence of traps for non-radiative energy dissipation such as xanthophyll pigments in an antennae pigment matrix (Bilger and Björkman 1990; Schreiber 2004). NPQ is induced by the formation of a proton gradient across the thylakoid membrane $(\Delta \mathrm{pH})$ and is associated with the operation of a xanthophyll cycle, which converts epoxidised to deepoxidised forms of xanthophylls (Lavaud 2007). For NPQ to be operational after dark exposure, there must a significant level of xanthophyll cycle pigments retained in the dark-adapted cells. Throughout the current study, the $10^{\circ} \mathrm{C}$ treatment produced the lowest maximum NPQ values and the rates of decline following dark exposure were always fastest. There were mostly significant differences between the initial and final values and between the different temperature treatments of all species in both experiments, and the two cooler treatments, -2 and $4^{\circ} \mathrm{C}$, mostly had higher values of maximum NPQ at the end of the dark incubation. Most change in NPQ occurred more rapidly than could be resolved in the monthly sampling interval, and in some cases, a significant peak in maximum NPQ occurred within the first 1-2 weeks of dark exposure. Many microalgal taxa, including sea ice algae, possess a fully functioning xanthophyll cycle that is capable of effective quenching even under low temperatures (Kudoh et al. 2003; Griffith et al. 2009). The current study suggests that warmer temperatures in the dark limit the capacity of microalgae to quench excess energy and thus avoid photosystem damage.

While $\mathrm{Fv} / \mathrm{Fm}$ recovery results were generally mostly inconclusive, recovery rates of NPQ following dark exposure were significant. NPQ consistently recovered from dark exposure, which suggests that the xanthophyll cycle was not impacted by dark incubation. Interestingly, NPQ recovery rates appear to be species specific. Recovery rates of $F$. cylindrus $\left(1.40 \mathrm{E}-5 \pm 3.46 \mathrm{E}-6 \mathrm{~s}^{-1}\right.$ to $5.38 \mathrm{E}-$ $6 \pm 3.46 \mathrm{E}-6 \mathrm{~s}^{-1}$ ) in the monthly sampling interval experiment were an order of magnitude lower than those 
of $T$. antarctica $\left(1.24 \mathrm{E}-4 \pm 8.10 \mathrm{E}-6 \mathrm{~s}^{-1}\right.$ to $1.57 \mathrm{E}-$ $4 \pm 1.15 \mathrm{E}-4 \mathrm{~s}^{-1}$ ), which in turn were an order of magnitude lower than those of E. kjellmanii (3.53E$3 \pm 4.46 \mathrm{E}-3 \mathrm{~s}^{-1}$ to $4.50 \mathrm{E}-3 \pm 3.78 \mathrm{E}-3 \mathrm{~s}^{-1}$ ). This demonstrates that individual species are likely to show species-specific xanthophyll cycle parameters such as rate constants, extent and kinetics of de-epoxidation (Lavaud et al. 2004). This result was mirrored in a study of winter sea ice algae in McMurdo Sound by McMinn et al. (2010). There, different species, under the same conditions, demonstrated dramatically different rates of both NPQ and rETR.

In addition to being a key structural component in the formation of cell membranes, carbohydrates provide an important source of stored energy and typically comprise $20-40 \%$ of the cellular dry weight in phytoplankton (Panagiotopoulos and Sempéré 2005). Although the TPTZ method of carbohydrate analysis can separate intracellular mono- and polysaccharides, only the concentration of dissolved free monosaccharides that can be water-extracted from cells preserved on filters is reported here. Unlike the polysaccharide fraction of the carbohydrate pool, which can fluctuate in response to factors such as diurnal light variation (van Oijen et al. 2003; van Oijen 2004) or the availability of iron (van Oijen et al. 2005), the concentration of water-extractable, the monosaccharide fraction of the carbohydrate pool generally remains stable in phytoplankton that are photosynthetically active. In diatoms, the storage carbohydrate is $\beta$-1,3-glucan, which is synthesised from the monosaccharides produced during photosynthesis enabling continued growth in the dark by providing energy and carbon skeletons for protein synthesis (Granum and Myklestad 1999; van Oijen et al. 2005; Alderkamp et al. 2007). It is thus particularly interesting in the current study that a stable monosaccharide pool was maintained by each species in the absence of photosynthesis. Despite the significant decline in the photosynthetic parameters Fv/Fm, rETRmax and variation in the ability of the cells to recover when re-exposed to light, TPTZ analysis highlights the ability of Antarctic diatoms to limit the consumption of carbohydrates in the absence of photosynthesis. However, the relatively stable carbohydrate concentrations observed for each species in this study clearly warrants further investigation, particularly if the experimental period is extended and both the mono- and polysaccharide fractions of the carbohydrate pool are determined.

The standard errors and standard deviations in most of the measurements were comparatively large. Some of the variation is likely to result from the inhomogeneous nature of the original sample. The biomass in the samples was also relatively low, and this would have influenced the noise level in measuring the photosynthetic parameters with the PAM fluorometer. Addition replication would have been advantageous but limits were imposed by the time it took to process the 54 samples from each sampling event.

Our results demonstrate that there is little difference in survival and recovery rates for increases in temperature up to $4^{\circ} \mathrm{C}$. Only at $10^{\circ} \mathrm{C}$ do changes in these rates become significantly lower. This suggests that forecast sea temperature increases of up to $2^{\circ}$ by 2010 (Peck 2005) are unlikely to have a major impact on dark survival and recovery of Antarctic microalgae. Although these results are indicative, we only examined diatoms isolated from sea ice and so a greater taxonomic diversity would need to be examined before definitive conclusions could be reached on the response of the phytoplankton or benthic microalgae communities.

\section{Summary}

Based on our observations, many Antarctic diatom species have the ability to survive long periods in the dark and then recover. Survival appears to be largely independent of moderate increases $\left(-2\right.$ to $\left.4^{\circ} \mathrm{C}\right)$ in temperature and only at environmentally unrealistic temperatures increases (e.g. $10^{\circ} \mathrm{C}$ ) do significant impacts appear. If these results are found to be similar in other species of microalgae, then it is possible that there will be little effect of increasing water temperatures on diatoms during the Antarctic winter.

Acknowledgments Funding for this project was from an Australian Research Council (ARC) Discovery Grant. We would also like to thank Helen Bond (IMAS) for assistance with culturing.

\section{References}

Alderkamp AC, Buma AGJ, van Rijssel M (2007) The carbohydrates of Phaeocystis and their degradation in the microbial food web. Biogeochem 83:99-118

Andreoli C, Moro I, La Rocca N, Dalla Valle L, Masiero L, Rascio N, Dalla Vecchia F (2000) Ecological, physiological and biomolecular surveys on microalgae from Ross Sea (Antarctica). Ital J Zool 67:147-156

Antia NJ (1976) Effects of temperature on the darkness survival of marine microplanktonic algae. Microb Ecol 3:41-54

Antia NJ, Cheng JY (1970) The survival of axenic cultures of marine planktonic algae from prolonged exposure to darkness at $20^{\circ} \mathrm{C}$. Phycol 9:179-183

Baldisserotto C, Ferroni L, Andreoli C, Fasulo MP, Bonora A, Pancaldi S (2005a) Dark-acclimation of the chloroplast in Koliella antarctica exposed to a simulated austral night condition. Arctic Antarctic Alpine Res 37:146-156

Baldisserotto C, Ferroni L, Moro I, Fasulo MP, Pancaldi S (2005b) Modulations of the thylakoid system in snow xanthophycean alga cultured in the dark for two months: comparison between microspectrofluorimetric responses and morphological aspects. Protoplasma 226:125-135

Bilger W, Björkman O (1990) Role of the xanthophyll cycle in photoprotection elucidated by measurements of light-induced 
absorbance changes, fluorescence and photosynthesis in leaves of Hedera canariensis. Photosynth Res 25:173-185

Botsford LW, Castilla JC, Peterson CH (1997) The management of fisheries and marine. Ecosys Sci 277:509-515

Bunt JS, Lee CC (1972) Data on the composition and dark survival of four sea-ice microalgae. Limnol Oceanog 17:458-461

Cullen JJ, Davis FF (2003) The blank can make a big difference in oceanographic measurements. Limnol Oceanograph Bull 12:29-35

Davison IR (1991) Environmental effects on algal photosynthesis: temperature. J Phycol 27:2-8

Demmig-Adams B, Adams WW (1992) Photoprotection and other responses of plants to high light stress. Ann Rev Plant Physiol Plant Mol Biol 43:599-626

Doucette GJ, Fryxell GA (1983) Thalassiosira antarctica: vegetative and resting stage chemical composition of an ice-related marine diatom. Marine Biol 78:1-6

Eicken $H$ (1992) The role of sea ice in structuring antarctic ecosystems. Polar Biol 12:3-13

Falkowski PG, Raven JA (2007) Aquatic photosynthesis, 2nd edn. Blackwell Science, Oxford

Ferroni L, Baldisserotto C, Zennaro V, Soldani C, Fasulo M, Pancaldi $S$ (2007) Acclimation to darkness in the marine chlorophyte Koliella antarctica cultured under low salinity: hypotheses on its origin in the polar environment. Eur J Phycol 42:91-104

Fiala M, Oriol L (1990) Light-temperature interactions on the growth of Antarctic diatoms. Polar Biol 10:629-636

Franklin DJ, Choi CJ, Hughes C, Malin G, Berges JA (2009) Effect of dead phytoplankton cells on the apparent efficiency of photosystem II. Mar Ecol Prog Ser 382:35-40

Granum E, Myklestad SM (1999) Effects of $\mathrm{NH}_{4}{ }^{+}$assimilation on dark carbon fixation and $\beta$-1,3-glucan metabolism in the marine diatom Skeletonema costatum (Bracillariophyceae). J Phycol 35:1191-1199

Griffith GP, Vennell R, Lamare MD (2009) Diadinoxanthin cycle of the bottom ice algal community in spring in McMurdo Sound, Antarctica. Polar Biol 32:623-636

Guillard RR (1975) Culture of phytoplankton for feeding marine invertebrates. In: Smith WL, Chanley MH (eds) Culture of marine invertebrate animals. Plenum Press, New York, pp 26-60

Gunnar Ö (1983) Effects of low temperature on photosynthesis. Plant Cell Environ 6:281-300

Holm-Hansen O, Riemann B (1978) Chlorophyll $a$ determination: improvements in methodology. Oikos 30:438-447

Holm-Hansen O, Lorenzen CJ, Holmes RW, Strickland JDH (1965) Fluorometric determination of chlorophyll. ICES J Mar Sci 30:3

Hung CC, Santschi PH (2001) Spectrophotometric determination of total uronic acids in seawater using cation-exchange separation and pre-concentration lyophilization. Anal Chim Acta 427:111-117

Jasby AD, Platt T (1976) Mathematical formulation of the relationship between photosynthesis and light for phytoplankton. Limnol Oceanog 21:540-547

Knox GA (2006) Biology of the southern Ocean. CRC Press, Baton Roca

Kok B (1956) On the inhibition of photosynthesis by intense light. Biochim Biophys Acta 21:234

Kottmeier ST, Sullivan CW (1988) Sea ice microbial communities (SIMCO). IX. Effects of temperature and salinity on rates of metabolism and growth of autotrophs and heterotrophs. Polar Biol 5:293-304

Kudoh S, Imura S, Kashino Y (2003) Xanthophyll-cycle of ice algae on the sea ice bottom in Saroma Ko lagoon, Hokkaido, Japan. Polar Biosci 16:86-97

Lavaud J (2007) Fast regulation of photosynthesis in diatoms: mechanisms, evolution and ecophysiology. Funct Plant Sci Biotechnol 1:267-287
Lavaud J et al (2004) General features of photoprotection by energy dissipation in planktonic diatoms (Bacillariophyceae). J Phycol 40:130-137

Lizotte MP (2001) The contributions of sea ice algae to Antarctic marine primary production. Am Zool 41:57-73

Lizotte MP, Sullivan CW (1992) Biochemical-composition and photosynthate distribution in sea ice microalgae of McMurdoSound, Antarctica-evidence for nutrient stress during the spring bloom. Antarctic Sci 4:23-30

Lüder UH, Knoetzel J, Wiencke C (2001) Acclimation of photosynthesis and pigments to seasonally changing light conditions in the endemic Antarctic red macroalga Palmaria decipiens. Polar Biol 24:598-603

Lüder UH, Wiencke C, Knoetzel J (2002) Acclimation of photosynthesis and pigments during and after six months of darkness in Palmaria decipiens (Rhodophyta)-a study to simulate Antarctic winter sea ice cover. J Phycol 38:904-913

McConville MJ (1985) Chemical composition and biochemistry of sea ice microalgae. In: Horner RA (ed) Sea ice biota. CRC Press, Boca Raton, Florida, pp 105-129

McMinn A, Hattori H (2006) Effect of time of day on the recovery from light exposure in ice algae from Saroma Ko lagoon, Hokkaido. Polar Biosci 20:30-36

McMinn A, Hegseth EN (2004) Quantum yield and photosynthetic parameters of marine microalgae from the southern Arctic Ocean, Svalbard. J Mar Biol Assoc UK 84:865-871

McMinn A, Martin A, Ryan K (2010) Phytoplankton and sea ice biomass and physiology during the transition between winter and spring (McMurdo Sound, Antarctica). Polar Biol 33:1547-1556

Meiners K, Papadimitriou S, Thomas D, Norman L, Dieckmann G (2009) Biogeochemical conditions and ice algal photosynthetic parameters in Weddell Sea ice during early spring. Polar Biol 32:1055-1065

Mock T, Hoch N (2005) Long-term temperature acclimation of photosynthesis in steady-state cultures of the polar diatom Fragilariopsis cylindrus. Photosynth Res 85:307-317

Morgan-Kiss RM, Ivanov AG, Williams J, Khan M, Huner NPA (2002) Differential thermal effects on the energy distribution between photosystem II and photosystem I in thylakoid membranes of a psychrophilic and a mesophilic alga. BBA Biomembranes 1561:251-265

Morgan-Kiss RM, Priscu JC, Pocock T, Gudynaite-Savitch L, Huner NPA (2006) Adaptation and acclimation of photosynthetic microorganisms to permanently cold environments. Microbiol Mol Biol Rev 70:222-252

Myklestad SM, Skånøy E, Hestmann S (1997) A sensitive and rapid method for analysis of dissolved mon- and polysaccharides in seawater. Mar Chem 56:279-286

Oeltjen A, Krumbein WE, Rhiel E (2002) Investigations on transcript sizes, steady state mRNA concentrations and diurnal expression of genes encoding fucoxanthin chlorophyll a/c light harvesting polypeptides in the centric diatom Cyclotella cryptica. Plant Biol 4:250-257

Oliver RL, Whittington J, Lorenz Z, Webster IT (2003) The influence of vertical mixing on the photoinhibition of variable chlorophyll a fluorescence and its inclusion in a model of phytoplankton photosynthesis. J Plank Res 25:1107-1129

Oquist G, Huner NPA (2003) Photosynthesis of overwintering evergreen plants. Ann Rev Plant Biol 54:329-355

Palmisano AC, Sullivan CW (1982) Physiology of sea ice diatoms. 1. Response of 3 polar diatoms to a simulated summer-winter transition. J Phycol 18:489-498

Palmisano AC, Sullivan CW (1983) Sea ice microbial communities (SIMCO) I. Distribution, abundance and primary production of microalgae in McMurdo Sound, Antarctica. J Phycol $18: 489-498$ 
Palmisano AC, Soohoo JB, Sullivan CW (1985) Photosynthesisirradiance relationships in sea ice microalgae from McMurdo Sound, Antarctica. J Phycol 21:341-346

Panagiotopoulos C, Sempéré R (2005) Analytical methods for the determination of sugars in marine samples: a historical perspective and future directions. Limnol Oceanog 3:419-454

Pankowski A, McMinn A (2009) Development of immunoassays for the iron- regulated proteins Ferredoxin and flavodoxin in polar microalgae. J Phycol 45:771-783

Peck LS (2005) Prospects for surviving climate change in Antarctic aquatic species. Frontiers Zool 2:2-9

Peters E (1996) Prolonged darkness and diatom mortality: II. Marine temperate species. J Experimen Mar Biol Ecol 207:43-58

Peters E, Thomas DN (1996) Prolonged darkness and diatom mortality I: Marine Antarctic species. J Experimen Mar Biol Ecol 207:25-41

Platt T, Gallegos CL, Harrison WG (1980) Photoinhibition of photosynthesis in natural assemblages of marine phytoplankton. J Mar Res 38:687-701

Ralph PJ, Gademann R (2005) Rapid light curves: a powerful tool to assess photosynthetic activity. Aquatic Bot 82:222-237

Ralph PJ, McMinn A, Ryan KG, Ashworth C (2005) Short-term effect of temperature on the photokinetics of microalgae from the surface layers of Antarctic pack ice. J Phycol 41:763-769

Schreiber U (2004) Pulse-amplitude-modulation (PAM) fluorometry and saturation pulse method: an overview. In: Papageorgiou GC (ed) Chlorophyll $a$ fluorescence a signature of photosynthesis. Springer, Dordrecht, The Netherlands, pp 279-319

Thomas DN, Dieckmann GS (2002) Antarctic sea ice-a habitat for extremophiles. Science 295:641-644

Trenerry LJ, McMinn A, Ryan KG (2002) In situ oxygen microelectrode measurements of bottom-ice algal production in McMurdo Sound, Antarctica. Polar Biol 25:72-80

Turner J, Colwell SR, Marshall GJ, Lachlan-Cope TA, Carleton AM, Jones PD, Lagun V, Reid PA, Iagovkina S (2005) Antarctic climate change during the last 50 years'. Intern J Climatol 25:279-294

van Oijen $T$ (2004) Iron and light limitation of carbohydrate production by phytoplankton in the Southern Ocean. Doctoral thesis. University of Groningen, The Netherlands

van Oijen T, van Leeuwe MA, Gieskes WWC (2003) Variation of particulate carbohydrate pools over time and depth in a diatomdominated plankton community at the Antarctic Polar Front. Polar Biol 26:195-201

van Oijen T, Veldhuis MJW, Gorbunov MY, Nishioka J, van Leeuwe MA, de Baar HJW (2005) Enhanced carbohydrate production by Southern Ocean phytoplankton in response to in situ iron fertilization. Mar Chem 93:33-52

Wulff A, Roleda MY, Zacher K, Wiencke C (2008) Exposure to sudden light burst after prolonged darkness - a case study on benthic diatoms in Antarctica. Diatom Res 23:519-532 